\title{
TECHNOLOGY - THE KEY TO SUCCESS IN BUSINESS ENGLISH CLASSES
}

\author{
Cristina-Laura Abrudan 325 \\ Ioana-Claudia Horea ${ }^{326}$
}

https://doi.org/10.31410/itema.2018.959

\begin{abstract}
Nowadays we witness a steady increase in the appearance of all kinds of technological equipments that can help us, teachers as well as students, that improve our work in class. We are living in a world dominated by the constant appearance of all kinds of technological inventions which contribute, more or less, to the way English as a foreign language is taught nowadays. The learning tools for teaching English have constantly been subject to innovation. The situation is the same when talking about a sensitive issue that is represented by mastering the language of Business English. During recent years the necessity of vocabulary teaching has gained more and more importance and, as a consequence, the appearance of all kinds of methods regarding teaching vocabulary has been subject to different debates between teachers of Business English. Vocabulary acquisition is utmost important since, in order to communicate fluently and accurately in a foreign language, mastering a large number of words and moreover mastering a large vocabulary in a certain domain, in our case the field of Business English, represents a necessary step. The appearance of different kinds of technological "helpers" has made our work way easier than it used to be just a couple of years before.

In order to gain fluency and efficiency in speaking a foreign language, teachers have to make use of the technological devices that seem to be extremely attractive to students and their use seems to be somehow a key to success. The aim of the present paper is to throw some light on more efficient and entertaining ways of teaching Business English to students of Economics, dealing with different Business English related materials. The role of the teacher, the need of supportive materials and the necessity of having a possible logical alternative to learning have also been analyzed throughout the paper. The process of teaching as well as the process of learning can be undergone with the help of some attractive technological inventions, which seem to be more and more fashionable. The diversity of the learning activities can help us enhance and expand our knowledge of the most commonly used Business English vocabulary, grammatical structures and to develop the specific language skills. The emerging technology does not undermine the traditional ways of teaching a foreign language. On the contrary, it comes as an element that supports and completes this complex process of teaching and acquiring a foreign language. Our experience proves that the use of technology in teaching Business English has led to more interesting, more dynamic and more challenging classes. Thus, in our digital world, where everything is controlled and dominated by the Internet and constant appearance of newer and smarter technological inventions, their contribution to the methods of Business language teaching is undeniable.
\end{abstract}

Keywords: teaching, technology, language, tools

\footnotetext{
${ }^{325}$ Unversity of Oradea, Faculty of Economics, Oradea, str. Universitatii, nr.3-5, Romania

${ }^{326}$ Unversity of Oradea, Faculty of Economics, Oradea, str. Universitatii, nr.3-5, Romania
} 
$\mathrm{W}$

e live in a digital world and technology is everywhere: it is in our offices, it is in our homes, it is in our lives; actually it has invaded (in a benefic way) our entire system of working as human beings. The technological inventions and the existence of the Internet have brought about great contributions in the field of foreign language teaching. Thus, it is no wonder the technological devices are nowadays an integral part of our language classes. Our lives are characterized by being accelerated, so it is no wonder that our students have to face new demands and have to be very well prepared for their future careers. Along with the changing of the methods used by the teachers in class, the 20th century has brought about important changes in the tradition of English language teaching. This process is constantly developing through the launching of newer and newer applications and devices all the time. Technology has to be integrated in classes, even though the changes brought to the act of teaching and learning can be both positive and negative. Teaching a foreign language is a challenging and often difficult process so, the teachers have to find out the most suitable technological aid and to discover how technology should be used in order to have a positive impact in class. Students must be prepared for their future roles in the society, no matter in what field they will activate; thus, the teachers as well as the educators sense the potential that technology has in increasing the motivation in learning foreign languages, by engaging the learners and improving the outcome of this process. All the persons involved in the process want to achieve the success of the endeavor of learning a foreign language, a process that is influenced by various factors that finally must lead to a positive outcome. During the history of foreign language teaching, a lot of methods have come to light; thus, teachers have to determine the most effective and suitable method of teaching and this process implies time and effort consumption. Technology has always been there, in the teaching and learning environment, one form or another, facilitating the students' learning experience.

\section{Some examples in the history of foreign language teaching}

The use of technology and teaching/learning a foreign language have always been related to each other, since we know that there have been language laboratories early in the $60 \mathrm{~s}$ and $70 \mathrm{~s}$ of the last century. Years ago language laboratories used to consist of small cabinets for students, having headphones for each one, a microphone and a cassette while the teacher was monitoring the students' activity. The creation of the language laboratories has represented a first step in the connection of the technology to the language learning process. If five hundred years ago Latin was the language of trade and education, nowadays English is the most widely studied language in the world. In Ancient times, Latin was taught by translating passages from the first language to the second one and vice versa. This has been considered to be a standard language teaching method. In 1982 Asher and James consider that "methods are the combination of techniques that are used and plasticized by the teachers in the classroom, in order to teach their students and the approaches are the philosophies of teachers about language teaching that can be applied in the classroom by using different techniques of language teaching" 327.

The structural approach - the next method that appeared in the history of language teaching - is mainly based on the techniques of the direct method but putting an emphasis on reading and writing. This method has a strong argument in the fact that we have to teach students the arrangement of the words in order to form a pattern that may be meaningful.

${ }^{327}$ Asher J. , James, D., Learning Another Language Through Actions, Los Gatos, 1982; 
The oral approach appeared somewhere between the 1930s and the 1960s being developed by the British linguists Harold Palmer and A.S.Hornsby. The selection of the material and its presentation and, of course, the context in which it is presented, are key factors, actually key differences between the oral approach and the direct method. Although the teachers nowadays are not aware of the importance of this method in the history of second language teaching, its role is undoubtedly great. The need for communication has led to the appearance of this method, which is not actually a method in itself, but an approach which goes beyond theorizing, transcending the boundaries of theory. Thus, not only grammatical and vocabulary structures are important, but the focus is put on the elements that compose the entire process of communication. Learners are engaged in the use of the language for meaningful purposes, in a pragmatic and functional way.

In the 1970s, Chomsky's revolution in linguistics underlined the importance of the "deep structure" of language, talking also about the affective and interpersonal nature of the process of learning from a psychological point of view. As a result, new methods appeared, being based on the psychological factors in the process of language learning.

The above ones represent just a few examples that have been selected by us from the various examples that exist in the history of foreign language teaching, in order to emphasize the constant concern of linguists, teachers and also psychologist to make the endeavor of learning/teaching a foreign language as easy and accessible as possible. Back then, technology was not present in the lives of the people who wanted to learn a foreign language while nowadays the development of the language skills started to depend on the existing technology. The number of learners is increasing and along with it the process of teaching is influenced by the modern tools and the technology that is at hand. E-learning platforms, videos, podcasts, applications and a huge number of websites are accessible currently and more and more teachers use these useful tools to make the process of learning diversified and easier. An increase in the quality of teaching and learning processes has been noticed along with the implementation of a wide range of multimedia that can avoid the routine and boredom of the same type of exercises that can be solved in a traditional course book. These traditional materials offer open-close exercises, rephrasing exercises, or translation exercises which do not give students the chance of practicing the spoken language. The issue of the speaking skills in a foreign language has long been debated, as this is actually the final goal of teaching and learning a foreign language. The sense of real communication can be achieved by using new broadcasts, interviews, songs that students can listen to. Due to the fact that nowadays almost everyone owns a smartphone or a laptop, the activity of creating a podcast or recording is at hand to almost everybody, thus having the chance to practice the pronunciation. The development of the listening skills but also the expansion of the vocabulary and language patterns can be expanded by using videos, songs or documentaries. The digital versions of crosswords, Scrabble or hangman represent a good source of both learning and entertainment for all age groups. Moreover, the development of the writing skills can be achieved by encouraging students to create blogs as they find this activity encouraging and also engaging as they can write about the subject they find interesting. The idea that a larger audience, and not only the teacher can read, the student's virtual journals make them put a bigger effort in the act of writing. The positive influence comes also from the fact that they get feedback from a larger audience. But if there are some students who are reluctant to writing weekly in a blog, they can be encouraged in having at least digital portfolios of their best works.

The use of new technologies, such as a laptop, a projector, an interactive board and also the access to Internet make lessons more accessible for the teacher as well as for the students. The 
teacher can provide newer and more challenging materials which give students the possibility of attending actively the class, being more involved and satisfied with the obtained result. This is the main reason why it is crucial for teachers to use technology and multimedia since we are facing a generation that is opposed to the older one which underestimates and criticizes its importance. The benefits and the variety of the methods that can be approached in English classes, by introducing digital materials give teachers the possibility of adjusting the material to individual needs, expectations and interests. By raising the students' interest, the teachers provoke creative thinking and, thus, students are encouraged more and more to practice the language inside the classroom but also outside it, in familiar environments, not feeling isolated and breaking the language barriers. The fact that, the students are exposed to the requirements of the real world, allows them to develop skills that are needed in future workplaces. The authentic materials make students face the everyday usage of the language, in different life situations, thus preparing them for the future workplace's demands. Moreover, nowadays students can use different kinds of devices such as laptops, computers, tablets and smart phones to overcome the feeling of boredom in learning a foreign language. Monotony can be overcome since newer and more interesting materials can be accessed. The use of learning platforms help the students consolidate what they have already learnt, making them develop their own style and pace of learning. By relating to different authentic situations, students can also have insights of different fields of work and different aspects of living. But no matter which of these tools we use in classes, the role of the teacher is a challenging one since the teacher is the person in the front who designs and delivers the learning material, the learning tools and actually guides the entire learning experience. The fact that technology is there does not necessarily mean that it will be used efficiently. It depends on the teacher how it is used.

When teaching English as a second language, teachers must take into consideration the four basic language skills that must be developed: speaking, listening, reading, and writing. These skills can be divided into two main categories: input skills and output skills. Each of these skills has different educational tools that are suited with. The listening skill is supposed to be a main language skill as by listening students can acquire the vast majority of their education. Saricoban says that "listening plays a vital role in the student's language development" 328 . The listening comprehension can be achieved by the help of the computers, radio educational programs, use of CD players, etc. The reading skill is an important input skill as it represents the process of understanding the message of a written text. Constantinescu claims that "reading depends on the vocabulary and background knowledge of the learner in the second language, 329 .

The following lines will give teachers some ideas on how they can make meaningful use of the existing technology and how to choose the materials to be used in classes. Students are supposed to be good communicators in English when they graduate university; they have to be able to share thoughts, ideas in many forms and to discuss different situations of life. So, the communication and collaborative skills must work together. Moreover, they need to create clear images and to be able to convey them to their interlocutor. When we learn something, we store it in the short-term memory, being able later to bring the information to light by using some connectors to the existing knowledge. Teachers can support their students in this process by organizing the information, by using digital learning resources and computers that prove to be at hand. The mental representations of the students are done by the help of the digital learning resources, processing content and even learning activities, information being presented by the

\footnotetext{
${ }^{328}$ Saricoban A., The Teaching of Listening, The Internet TESL Journal, 1999;

${ }^{329}$ Constantinescu A. I., Using Technology to Assist Vocabulary Acquisition and Reading Comprehension, The Internet TESL Journal, 2007;
} 
use of audio recordings, videos, texts, and so on. In 2008 Mayer claimed that "Research on multimedia learning have demonstrated more positive outcomes for students who learn from resources that effectively combine words and pictures, rather than those that include words alone." When the students interact with the information provided through different resources, they process it and store it in the working memory. And research shows that the interaction between the students and the digital resources create a more meaningful learning activity than the one created by the teacher. Although these resources can be very attractive to students, they not always represent a learning support in English classes. The teacher needs to know how to present the resources themselves and how to integrate the information, making use of sound educational principles. John Sweller, in 1988, when talking about cognitive load theory, tells us that "the learning resources must be designed to reduce the load on our working memory in order for us to be able to construct schema". The construction of the frame is extremely important, and thus, all the activities that are not directly related to it have to be excluded. There are two other things that are crucial in choosing the digital learning materials: the experience of the learners and the complexity of the material that has to be in accordance with the level of the learners. Moreover the resources have to cover the topic that is being taught and the information has to be conveyed directly. When talking about the learning materials we include all types of materials including those ones which improve the speaking skills of the students. We all know that the communication is the process of conveying a message from the sender to the listener. The functions that both perform have to be positive ones: the sender has to put the message into words, into spoken language while the listener has to receive the message and understand the language of the message. There are several speaking activities available on the Internet, among which we mention: the use of voice chatting and the use of specialized programs. Besides developing the speaking skills of the students we can also insert writing activities supported by technology. And at this point things are a little bit easier. Although, for the students, writing activities are challenging, the use of the technology can make the process more enjoyable and much easier. The existing word processing programs can improve grammar skills and even the use of study of grammar can be a more motivating one in comparison with the traditional one.

In order to evaluate the benefits of using technology in learning English as a second language, we have undertaken a case study, by using a questionnaire form given to the students of the Faculty of Economics, from University of Oradea, Romania. The results of our study are the following:

- $\quad 85 \%$ of the students use technology in their everyday lives;

- $95 \%$ of the students consider that technology has helped them improve their English;

- $95 \%$ of the students consider that the use of the Internet improves their English vocabulary;

- $\quad 95 \%$ of the students consider that the use of the Internet helped them develop their writing skills;

- $85 \%$ of the students consider that the use of the Internet helped them develop their listening skills;

- $85 \%$ of the students consider that the use of the Internet helped them develop their speaking skills;

- $\quad 75 \%$ of the students prefer classes using technology to learn the English language.

The results of the case study that we have undertaken show us exactly that the majority of the students consider that the use of technology helps them improving their second language skills, preferring classes based on the help of the computer instead of the traditional ones. We have also noticed that there were some drawbacks regarding the traditional methods of learning a second language. The first and the most important, in our opinion, is that students consider these 
classes lacking the connection between theory and practice. And as we have already mentioned in the above lines, the ultimate goal of our classes is for our students to be able to express themselves in English in certain life situations. The second drawback is that the traditional method lacks motivation and the sense of excitement. Another drawback is that the traditional method is somehow teacher-focused, as the activities are based on the teacher and not on the students, while the modern technology used in the process of learning, give the significant role to the student. Another important drawback is that the conventional technical methods are way slower than the modern ways in learning English.

\section{Conclusions}

Technology represents an excellent support in teaching and learning a second language. It does not reject traditional methods but it comes as a completion of the entire process in the fact that it offers a wider range of knowledge forms. Thus, the language classes become more attractive, dynamic and interesting. Taking into consideration these aspects, the conclusion is absolutely obvious: we live in the era of the technology, thus, the process of learning English as a second language has to be based on modern technology that has to be continually updated. The instruction process has to contain attractive, demanding and up-to-date materials that can be achieved by the use of the modern technology. The devices used in classes can be regarded as a means of transferring the information to the learner and putting the learner in the situation of practicing the foreign language. They can be also regarded as a link between theory and practice, thus developing the language skills. Moreover, as there is a clear demand for technology in language classes among the students, the educational institutions should put a clear emphasis on the modernization of the technical capabilities, equipments and laboratories which represent a clear support in the complex process of learning a second language.

\section{References}

1. Asher J., James, D., Learning Another Language Through Actions, Los Gatos, 1982;

2. Constantinescu, A.I., Using Technology to Assist in Vocabulary Acquisition and Reading Comprehension. The Internet TESL Journal, 13(2), ;

3. Davies, G., Hewer, S. Introduction to New Technologies and How They Can Contribute to Language Learning and Teaching, Thames Valley University, 2012;

4. Hoven, D., A Model for Listening and Viewing Comprehension in Multimedia Environments. Language Learning \&Technology, 1999;

5. Kenworthy, R.C., Developing Writing Skills in a Foreign Language Via the Internet;

6. Saricoban, A., The Teaching of Listening, The Internet TESL Journal, 1999;

7. Sharma, P. Controversies in Using Technology in Language Teaching, Widener University Press, 2009;

8. Solanki, D., Use of Technology in English Language Teaching and Learning: An Analysis, IACSIT Press, Singapore, 2012;

9. Tafani V., Teaching English Through Mass Media, Acta Didactica, Napocensia, 2009. 